\section{- OPEN ACCESS}

\title{
Severe capillary leak syndrome with cardiac arrest triggered by influenza virus infection
}

\author{
Lotte Ebdrup, ${ }^{1}$ Kirk Druey, ${ }^{2}$ Trine Hyrup Mogensen ${ }^{1,3,4}$
}

\begin{abstract}
'Department of Infectious Diseases, Aarhus University Hospital, Aarhus, Denmark ${ }^{2}$ Laboratory of Allergic Diseases, National Institute of Allergy and Infectious Diseases, National Institutes of Health, Bethesda, Maryland, USA

${ }^{3}$ Department of Biomedicine,

Aarhus University, Aarhus,

Denmark

${ }^{4}$ Department of Clinical

Medicine, Aarhus University, Aarhus, Denmark
\end{abstract}

\section{Correspondence to}

Professor Trine Hyrup Mogensen, trine.mogensen@biomed.au.dk

Accepted 1 August 2018
Check for updates

(c) BMJ Publishing Group Limited 2018. Re-use permitted under CC BY-NC. No commercial re-use. See rights and permissions. Published by BMJ.

To cite: Ebdrup L, Druey K, Mogensen TH. BMJ Case Rep Published Online First: [please include Day Month Year]. doi:10.1136/bcr-2018 226108

\begin{abstract}
SUMMARY
Systemic capillary leak syndrome (SCLS), also known as Clarkson syndrome, is a rare disease with potential fatal outcome. The clinical picture involves leakage of fluid and protein from the bloodstream into peripheral tissues, resulting in hypoalbuminaemia, elevated haematocrit, oedema and hypotension. The spectrum of the symptoms ranges from discrete swelling/oedema of extremities to fulminant cardiogenic shock. We present a case with a 52-year-old man diagnosed with SCLS after being resuscitated from cardiac arrest, which was complicated by compartment syndrome. The severe episode of capillary leak was potentially triggered by influenza virus infection. With the benefit of hindsight, he presented with symptoms of SCLS 2 years prior the major acute episode. Here we describe this case and review some aspects of the literature on SCLS, with particular focus on the pathogenesis, treatment/prophylaxis and long-term physical and psychological complications.
\end{abstract}

\section{BACKGROUND}

Systemic capillary leak syndrome (SCLS), also known as Clarkson syndrome, is a rare disease with a potentially fatal outcome. The syndrome was first described by Dr Clarkson in 1960 in a patient with recurrent episodes of hypotension, subcutaneous swelling, anasarca and increasing haematocrit. ${ }^{1}$ Due to the central role of vascular leakage in the pathogenesis, the disease was named idiopathic SCLS (or Clarkson disease). Since then, more than 350 cases of SCLS have been described in the literature. ${ }^{2}{ }^{3}$ However, the fundamental pathogenesis of this entity remains largely unresolved. The diagnosis is made based on the presence of a triad of hypotension (systolic blood pressure $<90 \mathrm{~mm} \mathrm{Hg}$ ), haemoconcentration (haematocrit $>49 \%-50 \%$ in men and $43 \%-45 \%$ in women) and hypoalbuminaemia $(<3.0 \mathrm{~g} / \mathrm{dL}) .{ }^{3}$ A characteristic of SCLS is the presence of paraprotein (M component) in blood, also known as gammopathy of unknown significance (MGUS), in the majority of patients, although it is not required for the diagnosis of SCLS.

Due to the rarity of the disease and a general lack of recognition by clinicians, SCLS is probably underdiagnosed. The disease is sporadic and has been described most commonly in middle-aged Caucasians with an equal sex distribution, although cases have been reported in ethnic groups from around the world. The typical acute SCLS episode presents as hypotensive shock with intravascular volume depletion and haemoconcentration. Most patients rapidly develop peripheral oedema (anasarca) and hypoalbuminaemia following resuscitation with intravenous fluids due to plasma extravasation. Renal failure can occur due to acute kidney injury (AKI) during this 'leak' phase. Pleural, pericardial effusion, ascites and oedema of the gastrointestinal tract are sometimes present. Forty-eight to 96 hours later, fluids are mobilised from peripheral tissues into plasma with renormalisation of circulation and diuresis. ${ }^{3}$ The severity of attacks varies, and patients with severe episodes may also experience separate milder attacks characterised by fatigue, weakness, mild oedema and muscle discomfort. Similarly, the frequency of attacks is highly individual/variable, ranging from several mild attacks per week to up to intervals of 5-10years between flares. ${ }^{4}$ Complications of acute vascular leak in SCLS include acute renal failure, thrombosis/pulmonary embolism and compartment syndrome, which may lead to sensorimotor neuropathy, foot drop or amputation.

\section{CASE PRESENTATION}

Here we describe a 52-year-old man admitted to the intensive care unit (ICU) of our university hospital in February 2016 after 2-3 days of diffuse abdominal pain, which increased in intensity 5-6hours prior to collapse, unconsciousness and cardiac arrest. Medical history included evaluation in the haematology department, October 2014, for a 2-month history of headache and several days of pain and swelling in both calves, polycythemia, and a normal blood pressure; evaluation with ultrasound of the lower extremities, CT scan of thorax and abdomen and bone marrow histopathology (negative for JAK3 mutation) were negative. The following 1.5 years before the acute admission, the patient had experienced two episodes of moderate, unexplained swelling of legs or arms and complained of persistent headache; moreover, he was diagnosed with a mild depression and granted partial disability, allowing him to work fewer hours/week because of this (still undiagnosed) condition.

On admission to the ICU, the patient had cardiac arrest with pulseless electrical activity, hypotension, severe hypovolaemia and extreme hypoalbuminaemia $(0.8 \mathrm{~g} / \mathrm{dL})$, increased haemoglobin $(25.8 \mathrm{~g} /$ $\mathrm{dL}$ ) and haematocrit (0.56), all of which normalised within 6 hours (table 1). Coronary angiography was performed, which revealed patent coronary arteries and no underlying cardiac pathology that could account for his presentation. CT scan of the thorax, abdomen and cerebrum was without pathology. No pericardial or pleural effusions were visible. Massive fluid extravasation causing swelling of 
Table 1 Blood tests in 2014, 2016 (major leak) and 2017 (follow-up)

\begin{tabular}{|c|c|c|c|c|c|c|c|}
\hline & \multirow[b]{4}{*}{ Normal range } & \multicolumn{2}{|l|}{2014} & \multicolumn{3}{|l|}{2016} & \multirow[b]{4}{*}{2017} \\
\hline & & \multicolumn{2}{|l|}{ October } & \multicolumn{3}{|c|}{ February } & \\
\hline & & \multirow[b]{2}{*}{ 4th } & \multirow[b]{2}{*}{ 6th } & 12th & & 13th & \\
\hline & & & & 08:00 & $14: 00$ & 06:00 & \\
\hline Albumin & $3.6-4.5 \mathrm{~g} / \mathrm{dL}$ & 3.6 & 3.8 & $0.8 \mathrm{~L}$ & $3.2 \mathrm{~L}$ & $2.8 \mathrm{~L}$ & 4 \\
\hline Haemoglobin & $13.8-17.2 \mathrm{~g} / \mathrm{dL}$ & $19.3 \mathrm{H}$ & 8.3 & $25.8 \mathrm{H}$ & $10.3 \mathrm{~L}$ & $11.9 \mathrm{~L}$ & 16.6 \\
\hline EVF & $40-50 \%$ & $51 \mathrm{H}$ & 39 & $56 \mathrm{H}$ & $30 \mathrm{~L}$ & $35 \mathrm{~L}$ & 48 \\
\hline Creatinine & $60-105 \mu \mathrm{mol} / \mathrm{L}$ & 94 & 83 & $227 \mathrm{H}$ & $191 \mathrm{H}$ & $259 \mathrm{H}$ & 77 \\
\hline Sodium & $137-145 \mathrm{mmol} / \mathrm{L}$ & 137 & 141 & 141 & $147 \mathrm{H}$ & 144 & 140 \\
\hline Potassium & $3.5-4.6 \mathrm{mmol} / \mathrm{L}$ & 4.6 & 4 & 3.7 & $3.2 \mathrm{~L}$ & 4.6 & 4.2 \\
\hline Phosphate & $0.71-1.23 \mathrm{mmol} / \mathrm{L}$ & & & $4.09 \mathrm{H}$ & $2.89 \mathrm{H}$ & $2.59 \mathrm{H}$ & \\
\hline ALT & $10-70 \mathrm{U} / \mathrm{L}$ & 19 & 23 & $398 \mathrm{H}$ & $458 \mathrm{H}$ & $380 \mathrm{H}$ & 47 (June) \\
\hline TNT & $14 \mathrm{ng} / \mathrm{L}$ & & & $219 \mathrm{H}$ & $829 \mathrm{H}$ & $827 \mathrm{H}$ & \\
\hline Creatine kinase & $50-270 \mathrm{U} / \mathrm{L}$ & & & & $254 \mathrm{H}$ & $6266 \mathrm{H}$ & \\
\hline Myoglobin & $<75 \mu \mathrm{g} / \mathrm{L}$ & & & & $273 \mathrm{H}$ & $10936 \mathrm{H}$ & \\
\hline CRP & $<8 \mathrm{mg} / \mathrm{L}$ & 6.4 & 2.9 & 5.5 & 3.7 & $43 \mathrm{H}$ & 1.4 \\
\hline Leukocytes & $* 10^{9} / \mathrm{L}$ & 5.7 & 3.3 & $12.9 \mathrm{H}$ & 8.4 & 8.5 & 3.7 \\
\hline Thrombocytes & ${ }^{*} 10^{9} / \mathrm{L}$ & 211 & 174 & $106 \mathrm{~L}$ & $106 \mathrm{~L}$ & $98 \mathrm{~L}$ & 191 \\
\hline Lactate, arterial & $0.5-2.5 \mathrm{mmol} / \mathrm{L}$ & & & $8.2 \mathrm{H}$ & $14.8 \mathrm{H}$ & $4.7 \mathrm{H}$ & \\
\hline D-dimer & $<0.5 \mathrm{mg} / \mathrm{L}$ & & & $>20 \mathrm{H}$ & $>20 \mathrm{H}$ & $7.0 \mathrm{H}$ & \\
\hline INR/pp & $<1.2 / 0.6-1.3$ & $/ 1.2$ & $/ 1.2$ & $3.6 \mathrm{H}$ & $1.7 \mathrm{H}$ & 1.1 & \\
\hline APTT & $25-38 \mathrm{~s}$ & & & $>150 \mathrm{H}$ & $>134 \mathrm{H}$ & $45 \mathrm{H}$ & \\
\hline M-spike (plasma) mg/dL & & & & & & $\begin{array}{l}\text { Positive } \\
100\end{array}$ & $\begin{array}{l}\text { Positive (kappa lgG) } \\
520\end{array}$ \\
\hline Kappa chain & $0.33-1.94 \mathrm{mg} / \mathrm{dL}$ & & & & & $48 \mathrm{H}$ & \\
\hline Lambda chain & $0.57-2.63 \mathrm{mg} / \mathrm{dL}$ & & & & & 2.07 & \\
\hline Ratio kappa/lambda & $0.26-1.65$ & & & & & $2.31 \mathrm{H}$ & \\
\hline Complement C1q & $0.24-0.61 \mu \mathrm{g} / \mathrm{mL}$ & & & & & 0.35 & \\
\hline Complement C3c & $90-180 \mathrm{mg} / \mathrm{dL}$ & & & & & $0.4949 \mathrm{~L}$ & $129(2016)$ \\
\hline Complement C4 & $10-40$ mg/dL g/L & & & & & $0.088 \mathrm{~L}$ & $30(2016)$ \\
\hline $\lg A$ & $80-490 \mathrm{mg} / \mathrm{dL}$ & & & & & 109 & 140 \\
\hline $\lg G$ & $610-1490 \mathrm{mg} / \mathrm{dL}$ & & & & & $530 \mathrm{~L}$ & $1600 \mathrm{H}$ \\
\hline
\end{tabular}

ALT, alanine aminotransferase; APTT, activated partial thromboplastin time; CRP, C reactive protein; EVF, erythrocyte volume fraction; H, high; INR, international normalized ratio; L, low; TNT, troponine T.

both legs and a compartment syndrome developed, necessitating bilateral fasciotomies. Gastroscopy was performed and showed diffuse bleeding. Renal replacement therapy was initiated for AKI. Within the first 48 hours, inotropic support (milrinone), corticosteroids and broad-spectrum antibiotics (piperacillin/ tazobactam) were administered empirically as the primary diagnosis remained cryptic. Because the patient presented with acute hypotension, shock and cardiac arrest during peak influenza season, the patient was tested for influenza A and B following our institutional guidelines and was found to be positive for influenza A by PCR. Accordingly, oseltamivir treatment was initiated. Lab tests revealed positive paraprotein ( $\mathrm{M}$ component) with increased levels of kappa light chains, initially $100 \mathrm{mg} / \mathrm{dL}$, (most recently $520 \mathrm{mg} / \mathrm{dL}$, table 1 ). C-1 esterase inhibitor level was normal.

During the course of the episode, infection and necrosis of the anterior muscle of right lower leg at the fasciotomy site developed, necessitating debridement. As a result, long-term residual peroneal nerve paresis on right side persisted following the attack. During his prolonged hospitalisation, the infections (ventilator associated pneumonia and necrosis/infection of anterior extensor muscle compartment) eventually resolved, renal function was restored and the patient was discharged 41 days after admission.

\section{INVESTIGATIONS}

The most severe manifestations of SCLS are hypovolaemic shock and cardiac arrest. A history of localised oedema and increased haematocrit should alert the clinician and prompt further diagnostic. Serum albumin levels, haematocrit and blood pressure should be monitored frequently during an attack. M-component (blood and urine), complement C3/4, C1-esterase inhibitor levels and function must be measured, together with other parameters to exclude or confirm other diagnoses.

The patient was evaluated at the National Institutes of Health 18 months after the acute episode. Lab tests were repeated, including beta-2-microglobulin, C3/4, quantitative immunoglobulins and immunofixation electrophoresis (table 2). Cardiac MRI was normal.

\section{DIFFERENTIAL DIAGNOSIS}

Polycythemia vera was considered 2 years prior to the major capillary leak event.

In the acute phase, other reasons for shock (septic, cardiogenic, bleeding and so on) must be ruled out. Other rare causes of hypotension may include neuroendocrine tumours, inferior vena cava syndrome or coagulopathy. Likewise, hereditary angio-oedema may share features with SCLS and should be excluded by measuring C1 esterase inhibitor levels. Infections with filoviruses (eg, Ebola and 
Table 2 Evaluation at National Institutes of Health

\begin{tabular}{lllc}
\hline & Normal range & September 2017 \\
\hline Albumin & $4.3-5.5 \mathrm{~g} / \mathrm{dL}$ & 4.6 & \\
\hline Haemoglobin & $13.8-17.2 \mathrm{~g} / \mathrm{dL}$ & 16 & $\mathrm{H}$ \\
\hline EVF & $36 \%-48 \%$ & 49 & \\
M-spike (plasma, gamma) & $\mathrm{mg} / \mathrm{dL}$ & 400 & \\
\hline Kappa light chain & $0.33-1.94 \mathrm{mg} / \mathrm{dL}$ & 1.81 & \\
\hline Lambda light chain & $0.57-2.63 \mathrm{mg} / \mathrm{dL}$ & 0.98 & $\mathrm{H}$ \\
Ratio kappa/lambda & $0.26-1.65$ & 1.85 & \\
Complement C3 & $90-180 \mathrm{mg} / \mathrm{dL}$ & 116 & \\
Complement C4 & $10-40 \mathrm{mg} / \mathrm{dL}$ & 16 & $\mathrm{H}$ \\
\hline IgG & $700-1600 \mathrm{mg} / \mathrm{dL}$ & 2412 & \\
\hline Tryptase & $<11.5 \mathrm{ng} / \mathrm{mL}$ & 2.8 & $\mathrm{H}$ \\
\hline Beta-2-microglobulin & $0.9-1.7 \mathrm{ng} / \mathrm{mL}$ & 2.0 & \\
\hline
\end{tabular}

Within normal range: creatinine, sodium, potassium, ALT, creatine kinase, APTT, INR, $\lg A$ and $\lg M$.

APTT, activated partial thromboplastin time; ALT, alanine aminotransferase; EVF, erythrocyte volume fraction; $H$, high; INR, international normalized ratio; L, low.

dengue) can also present with features of vascular leak similar to Clarkson disease.

\section{TREATMENT}

The patient was started on intravenous immunoglobulin (IVIG) $(2 \mathrm{~g} / \mathrm{kg})$ at day 34 for the prevention of capillary leak syndrome. Since then, he has received a maintenance dose of IVIG $1 \mathrm{~g} / \mathrm{kg}$ every 4 weeks with a trough level of $\mathrm{IgG}$ around $1500 \mathrm{mg} / \mathrm{dL}$ and peak levels the day after IVIG administration of around $3000 \mathrm{mg} / \mathrm{dL}$. In accordance with the current guidelines, the patient receives no other prophylactic treatment.

\section{OUTCOME AND FOLLOW-UP}

Presently, 2 years after this major leak episode, the patient is in relatively good clinical condition and is receiving IVIG $1 \mathrm{~g} / \mathrm{kg}$ every 4 weeks with a through level of $\mathrm{IgG}$ around $1500 \mathrm{mg} / \mathrm{dL}$ and peak levels of around $3000 \mathrm{mg} / \mathrm{dL}$. He did, however, experience a few minor episodes of oedema/swelling of extremities interpreted as minor leaks despite prophylaxis with IVIG. Moreover, he has a remaining significant fatigue and mild cognitive disturbances and was diagnosed with mild depression. Another medical issue is that he also suffers from neuropathic pain in both legs and receives physiotherapy on a lifelong regular basis.

Finally, the patient is followed in the Department of Hematology with a diagnosis of MGUS. A bone marrow was performed without signs of malignancy. Paraprotein (M-component), Ig levels and other haematological parameters are measured every 3 months.

\section{DISCUSSION}

In this paper, we describe a male patient presenting with cardiac arrest who was subsequently diagnosed with SCLS. The case illustrates several aspects typical of SCLS, including potential trigger by virus infection, presence of a paraprotein, severe rhabdomyolysis and compartment syndrome during the acute phase, and finally persistent fatigue and smaller leaks, despite prophylaxis with IVIG. A recent multicentre study on 59 episodes of acute leaks in 37 patients with SCLS admitted to the ICU revealed that compartment syndrome developed in approximately $20 \%$ of episodes, whereas the overall mortality during acute attacks was around $19 \% .^{5}$
The pathogenesis of SCLS remains poorly understood, but the central pathology may include vascular endothelial dysfunction. Sera obtained from acute flares of SCLS reduce barrier function of healthy microvascular endothelial cells, whereas convalescent sera from the same patients do not. ${ }^{6}$ This suggests the presence of soluble mediators precipitating vascular leakage during acute SCLS flares. While allergic triggers are not typically associated with SCLS attacks, increasing evidence suggest that inflammation is often linked to leak episodes, and up to three out of four patients reported a viruslike prodromal illness preceding the leak. ${ }^{4}$ These included viral infections, such as influenza virus, respiratory syncytial virus and West Nile virus. ${ }^{7}$ Previously, a case report described the occurrence of SCLS triggered by influenza virus infection in a 40-year-old woman. This patient's presentation differed somewhat from ours, in that the respiratory symptoms of influenza were more prominent, and she did not experience cardiac arrest. $^{8}$ Moreover, elevated proinflammatory mediators, including interleukin-6, were measured during acute attacks. ${ }^{9}$ Intense physical exercise and exhaustion has been linked to disease flares in patients with SCLS, ${ }^{10}$ suggesting a potential role for metabolic stress in the induction of vascular barrier disruption. A genetic component has also been considered, although no specific mutations have been uniformly associated with SCLS thus far. One small genome-wide association study suggested a potential genetic link and identified a candidate susceptibility locus, but the number of patient included was too small to reach firm conclusions. ${ }^{11}$ Given the central common aspect of abnormal endothelial physiology, several studies have sought to address the abnormalities in angiogenic permeability factors, such as vascular endothelial growth factor A angiopoietin 2, which are increased transiently in sera during attacks. ${ }^{3}$ Intriguingly, because most patients do not have residual oedema during asymptomatic intervals, these findings suggest that endothelial barrier dysfunction is also transient, manifesting only around disease flares. ${ }^{3}$

One important question relates to the potential pathogenic role of the paraprotein present in most patients with SCLS. Purified IgG does not recapitulate the effects of acute SCLS sera on endothelial cells, suggesting that MGUS is an associated epiphenomenon and not directly related to pathogenesis. ${ }^{6}$ The risk of progression to myeloma is not increased compared with other patients with MGUS. Altogether, the pathogenesis underlying abnormal endothelial barrier function may involve both an intrinsic susceptibility to inflammatory mediators as well as extrinsic factors such as the paraprotein.

The treatment of acute episodes of SCLS remains primarily supportive as several strategies including corticosteroids, antihistamines, high dose aminophylline and anticytokine compounds (eg, infliximab) have been used with limited success. ${ }^{312}$ A recent multicentre study of patients with SCLS admitted to the ICU demonstrated that therapy of acute flares with high-volume intravenous fluids was independently associated with poorer outcomes. ${ }^{5}$ Although a beneficial effect of IVIG (1-2 g/ kg) during acute leaks has been suggested based on the study of a few patients, ${ }^{13}$ overall, its efficacy in the acute setting has not been established. ${ }^{5}$ In contrast, prophylactic administration of IVIG on a monthly basis clearly reduces the severity and frequency of episodes in most patients. ${ }^{414} \mathrm{~A}$ recent study provided evidence of increased survival of patients with SCLS receiving IVIG compared with those not treated with IVIG $^{15}$; it should be considered as current standard of care for this disease. Dosing varies from $0.4 \mathrm{~g} / \mathrm{kg} / \mathrm{month}$ to $2 \mathrm{~g} / \mathrm{kg} /$ month in different studies, although definite target peak or 
trough levels have been defined. Currently, a dose of $1-2 \mathrm{~g} / \mathrm{kg} /$ month is recommended, and due to the favourable side effect profile, IVIG is mostly recommended as monotherapy due to questionable/uncertain effect of other therapies (theophyllamine and terbutaline) combined with considerable side effects of those drugs. ${ }^{3}$ The mechanism of action of high-dose IVIG is currently unknown but may include anti-idiotypic effects on the paraprotein, neutralisation of proinflammatory cytokines and/or immunomodulatory effects, which have been described previously. ${ }^{316}$

Fatigue appearing as a pronounced periattack symptom is well established. However, whether subtler mental fatigue and cognitive disturbances occur in chronic or mild forms of SCLS with less severe leaks is not well understood. Typically, central nervous system oedema does not accompany acute episodes of SCLS, although patients are at increased risk of thromboembolic stroke due to haemoconcentration and increased serum viscosity. Our patient was diagnosed with mild depression prior to the major attack and cardiac arrest, and currently, he still suffers from mild cognitive symptoms and chronic headache. We speculate that minor long-term cognitive symptoms may be associated with SCLS in some patients.

\section{Patient's perspective}

During the years before my diagnosis I had a number of symptoms which prompted me to seek medical advice. I was referred to several different medical departments and SCLS was obviously a difficult diagnosis to make based on my very diverse symptoms. However, I have often considered why I was seen only by relatively young and inexperienced medical doctors. After my SCLS diagnosis I mostly see experienced doctors and I sometimes wonder, whether it might have made any difference had I met/been seen by a specialist before I experienced a severe attack of life-threatening capillary leakage? Since SCLS is such a rare disease and only sparse literature and documentation on this condition exist, it is essential for me to be involved in decisions regarding prophylaxis and treatment and to have the possibility to discus and express my concerns and priorities with my doctors. This certainly makes me more comfortable and less worried concerning my disease.

\section{Learning points}

- Localised oedema of unknown origin or episodes of increased haematocrit of unknown origin, consider systemic capillary leak syndrome (SCLS).

- In confirmed SCLS, IVIG prophylaxis (1-2 g/kg/month) is the standard of care.

- SCLS may associated with several clinical symptoms and sequelae, including fatigue, muscle pain, depression and recurrent episodes with minor or major leaks.

- Better understanding of the genetics and immunology underlying the exaggerated microvascular endothelial response to inflammation and physical stress leading to capillary leak syndrome may improve treatment and prophylaxis of the disease.

\section{CONCLUSIONS}

Further studies on the clinical attributes of SCLS as well as the basic molecular and cellular mechanisms of the disease will hopefully provide insight into this intriguing and serious medical condition. Understanding the genetic, immunological and pathophysiological mechanisms will help guide clinicians on treatment of acute attacks. Early recognition of this entity and prompt initiation of prophylaxis with IVIG will prevent further morbidity and potential fatalities in patients with SCLS.

Acknowledgements We would like to thank the patient and his family for contributing to this manuscript.

Contributors LE and THM diagnosed and cared for the patient. KD performed a second opinion evaluation of the patient and advised on follow-up and prophylactic treatment. THM drafted the first version of the manuscript; all authors read and approved the final version of the manuscript.

Funding The authors have not declared a specific grant for this research from any funding agency in the public, commercial or not-for-profit sectors.

Competing interests None declared.

\section{Patient consent Obtained.}

Provenance and peer review Not commissioned; externally peer reviewed.

Open access This is an open access article distributed in accordance with the Creative Commons Attribution Non Commercial (CC BY-NC 4.0) license, which permits others to distribute, remix, adapt, build upon this work non-commercially, and license their derivative works on different terms, provided the original work is properly cited and the use is non-commercial. See: http://creativecommons.org/ licenses/by-nc/4.0/

\section{REFERENCES}

1 Clarkson B, Thompson D, Horwith M, et al. Cyclical edema and shock due to increased capillary permeability. Am J Med 1960;29:193-216.

2 Eo TS, Chun KJ, Hong SJ, et al. Clinical presentation, management, and prognostic factors of idiopathic systemic capillary leak syndrome: a systematic review. J Allergy Clin Immunol Pract 2018;6:609-18.

3 Druey KM, Parikh SM. Idiopathic systemic capillary leak syndrome (Clarkson disease). J Allergy Clin Immunol 2017;140:663-70.

4 Gousseff M, Arnaud L, Lambert M, et al. The systemic capillary leak syndrome: a case series of 28 patients from a European registry. Ann Intern Med 2011;154:464-71.

5 Pineton de Chambrun M, Luyt CE, Beloncle F, et al. The clinical picture of severe systemic capillary-leak syndrome episodes requiring icu admission. Crit Care Med 2017:45:1216-23.

6 Xie Z, Ghosh CC, Patel R, et al. Vascular endothelial hyperpermeability induces the clinical symptoms of Clarkson disease (the systemic capillary leak syndrome). Blood 2012;119:4321-32.

7 Hsu P, Xie Z, Frith K, et al. Idiopathic systemic capillary leak syndrome in children. Pediatrics 2015;135:e730-e735.

8 Sousa A, Len 0 , Escolà-Vergé L, et al. Influenza A virus infection is associated with systemic capillary leak syndrome: case report and systematic review of the literature. Antivir Ther 2016;21:181-3.

9 Xie Z, Chan E, Yin Y, et al. Inflammatory markers of the systemic capillary leak syndrome (clarkson disease). J Clin Cell Immunol 2014;5:1000213.

10 Durand Bechu M, Rouget A, Recher C, et al. A systemic capillary leak syndrome (clarkson syndrome) in a patient with chronic lymphocytic leukemia: A case report in an out-ofhospital setting. Case Rep Emerg Med 2016;2016:1-3.

11 Xie Z, Nagarajan V, Sturdevant DE, et al. Genome-wide snp analysis of the systemic capillary leak syndrome (clarkson disease). Rare Dis 2013;1:e27445.

12 Dowden AM, Rullo OJ, Aziz N, et al. Idiopathic systemic capillary leak syndrome: novel therapy for acute attacks. J Allergy Clin Immunol 2009;124:1111-3.

13 Lambert M, Launay D, Hachulla E, et al. High-dose intravenous immunoglobulins dramatically reverse systemic capillary leak syndrome. Crit Care Med 2008;36:2184-7.

14 Xie Z, Chan EC, Long LM, et al. High-dose intravenous immunoglobulin therapy for systemic capillary leak syndrome (Clarkson disease). Am J Med 2015;128:91-5.

15 Pineton de Chambrun M, Gousseff M, Mauhin W, et al. INtravenous immunoglobulins improve survival in monoclonal gammopathy-associated systemic capillary-leak syndrome. Am J Med 2017;130:1219.e19-1219.e27.

16 Dézsi L, Horváth Z, Vécsei L. Intravenous immunoglobulin: pharmacological properties and use in polyneuropathies. Expert Opin Drug Metab Toxicol 2016:1343-58. 
Copyright 2018 BMJ Publishing Group. All rights reserved. For permission to reuse any of this content visit http://group.bmj.com/group/rights-licensing/permissions.

BMJ Case Report Fellows may re-use this article for personal use and teaching without any further permission.

Become a Fellow of BMJ Case Reports today and you can:

- Submit as many cases as you like

- Enjoy fast sympathetic peer review and rapid publication of accepted articles

- Access all the published articles

- Re-use any of the published material for personal use and teaching without further permission

For information on Institutional Fellowships contact consortiasales@bmjgroup.com

Visit casereports.bmj.com for more articles like this and to become a Fellow 